\title{
Criterion for High Temperature Failure and Grain Boundary Chemistry in Superplastic TZP
}

\author{
Hidehiro Yoshida ${ }^{1, * 1}$, Hitoshi Nagayama ${ }^{1, * 2}$, Akihide Kuwabara ${ }^{2}$ and Taketo Sakuma ${ }^{1, * 3}$ \\ ${ }^{1}$ Department of Advanced Materials Science, School of Frontier Science, The University of Tokyo, Tokyo 113-8654, Japan \\ ${ }^{2}$ Department of Materials Science and Engineering, Faculty of Engineering, Kyoto University, Kyoto 606-0033, Japan
}

Temperature and strain rate dependence on high temperature elongation to failure in fine-grained ceramics is phenomenologically explained from grain growth behavior during deformation and the superplastic flow behavior. The elongation to failure at temperatures between 1573 and $1773 \mathrm{~K}$ was analyzed for $2 \mathrm{~mol} \% \mathrm{TiO}_{2}$ and $2 \mathrm{~mol} \% \mathrm{GeO}_{2}$ co-doped tetragonal zirconia polycrystal (TZP), which exhibits excellent high temperature ductility. The improvement in the high temperature ductility in TZP is attributed to dopant cation segregation in the vicinity of the grain boundaries. The phenomenological analysis revealed that co-doping of $\mathrm{Ti}$ and Ge cations increases the grain size at the time of failure, as a parameter to describe a limit of an accommodation process for superplastic flow. The parameter of the critical grain size at the time of failure correlates well with the value of overlap population in cation-doped TZP model cluster obtained from a first-principle molecular orbital calculation. The covalent bond at the grain boundaries plays a critical role in the high temperature tensile ductility of TZP.

(Received January 21, 2004; Accepted April 12, 2004)

Keywords: tetragonal zirconia polycrystal, superplasticity, tensile ductility, grain boundary, molecular orbital calculation

\section{Introduction}

Fine-grained tetragonal $\mathrm{ZrO}_{2}$ polycrystal (TZP) is one of the most representative superplastic ceramics, which exhibit large tensile elongation at high temperature. ${ }^{1-7)}$ For instance, the elongation of $800 \%$ was obtained in TZP at $1823 \mathrm{~K}$ under the strain rate of $8.3 \times 10^{-5} \mathrm{~s}^{-1} .^{2)}$ More recently, it has been pointed out that the superplastic behavior such as flow stress and elongation to failure in TZP is sensitively affected by small amount of impurities. ${ }^{8-11)}$ TZP-2 mass $\% \mathrm{CaO}-$ 2 mass $\% \mathrm{TiO}_{2}$ exhibits the maximum elongation of $480 \%$ at a strain rate of $1.1 \times 10^{-3} \mathrm{~s}^{-1}$ at $1673 \mathrm{~K},{ }^{10)}$ and TZP$2 \mathrm{~mol}^{2} \mathrm{TiO}_{2}$ and $\mathrm{GeO}_{2}$ exhibits large elongation to failure of about $1000 \%$ at $1673 \mathrm{~K}$ and a strain rate of $1.3 \times$ $10^{-4} \mathrm{~s}^{-1}$.11)

Formerly, it was pointed out that the elongation to failure in superplastic ceramics can be described as a function of the Zener-Hollomon parameter of $\dot{\varepsilon} \exp (Q / R T)$, where $\dot{\varepsilon}$ is the strain rate, $Q$ is the activation energy for superplastic flow, and $R T$ is the gas constant times absolute temperature. ${ }^{12)}$ Since this parameter corresponds to high temperature flow stress under a constant grain size, the elongation to failure becomes larger with a decrease in the flow stress. However, many exceptions have later been found in superplastic ceramics. Figure 1 shows a comparison of stress-strain curves in (a) $2.5 \mathrm{~mol} \% \quad \mathrm{Y}_{2} \mathrm{O}_{3}$-stabilized TZP and (b) TZP5 mass $\%(7.8 \mathrm{~mol} \%) \quad \mathrm{TiO}_{2}$ under an initial strain rate of $1.3 \times 10^{-4} \mathrm{~s}^{-1}$ at temperatures between 1473 and $1823 \mathrm{~K}^{13)}$ In TZP, the flow stress is reduced as the temperature increases, and the elongation to failure becomes larger at higher temperatures up to $1823 \mathrm{~K}$. The flow stress in TZP$\mathrm{TiO}_{2}$ also decreases with increase in temperature, but the

\footnotetext{
${ }^{* 1}$ Present address: National Institute for Materials Science, Tsukuba 305-0047, Japan,

Corresponding author, E-mail: YOSHIDA.Hidehiro@nims.go.jp

${ }^{* 2}$ Graduate Student, The University of Tokyo

*3 Present address: National Institute for Academic Degrees and University Evaluation
}

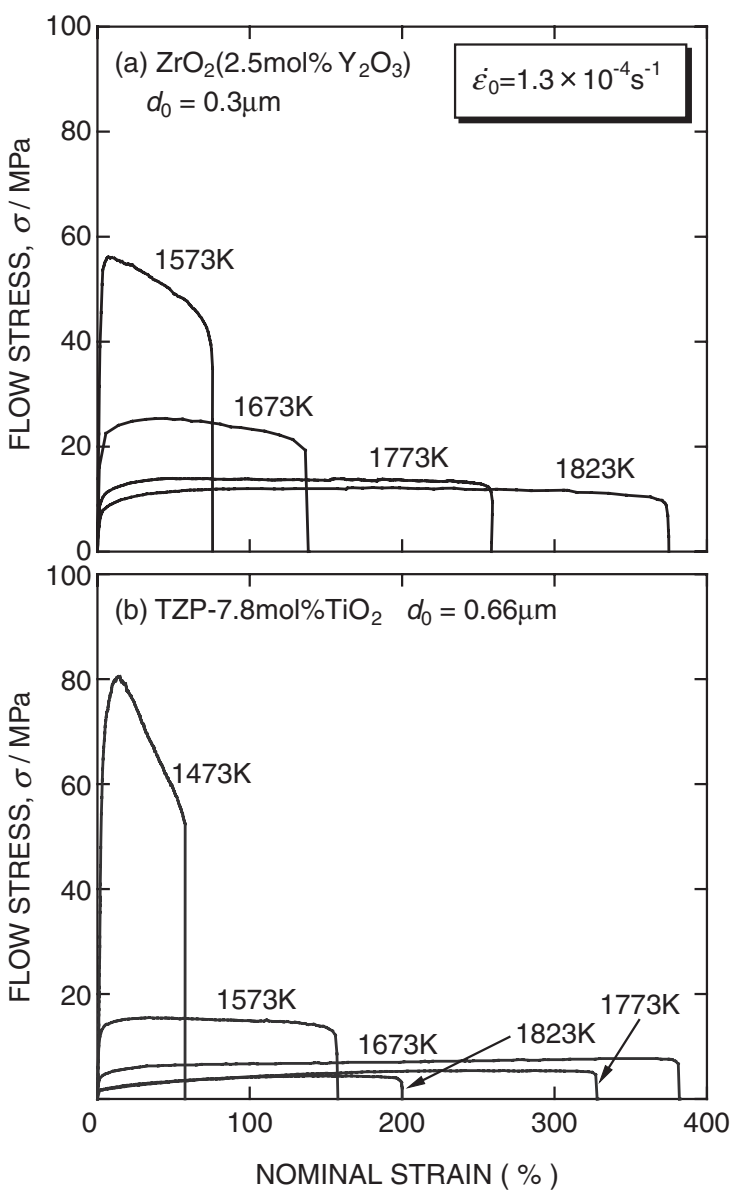

Fig. 1 Stress-strain curves in TZP (a) and TZP-5 mass $\%(7.8 \mathrm{~mol} \%) \mathrm{TiO}_{2}$ (b) at an initial strain rate of $1.3 \times 10^{-4} \mathrm{~s}^{-1}$ at temperatures between 1473 and $1823 \mathrm{~K}^{13)}$

elongation to failure in $\mathrm{TZP}-\mathrm{TiO}_{2}$ decreases with increase in temperature above $1673 \mathrm{~K}$. This fact indicates that the elongation to failure is not a simple function of the flow stress. The temperature and strain rate dependences on the 
high temperature tensile ductility in $\mathrm{TiO}_{2}$-added TZP were phenomenologically explained from the viewpoint of the grain size at the time of failure as a parameter of limitation of an accommodation process for superplastic flow. ${ }^{13)}$

On the other hand, a first principle molecular orbital calculation revealed that the tensile elongation to failure in ceramics correlates well with bond overlap population between anions and cations, which corresponds to covalent bond strength between atoms. ${ }^{14,15)}$ The change in the chemical bonding strength at grain boundaries must dominantly influence grain boundary diffusion and bond strength at the grain boundaries, and thus seems to be an important factor to determine the plastic flow in superplastic ceramics. However, the correlation between the interatomic reaction and the critical assessment for high temperature dutility has not been clarified yet. In the present study, the superplastic behavior was investigated in $2 \mathrm{~mol} \% \mathrm{TiO}_{2}$ and $2 \mathrm{~mol} \% \mathrm{GeO}_{2}$ co-doped TZP, which exhibits an excellent superplasticity. The grain size at failure as a criterion for high temperature tensile ductility will be discussed from the viewpoint of chemical bonding strength at the grain boundaries comparing with TZP and $\mathrm{TZP}-7.8 \mathrm{~mol} \% \mathrm{TiO}_{2}$.

\section{Experimental Procedure}

The material used in this study was $2 \mathrm{~mol} \% \mathrm{TiO}_{2}$ and $2 \mathrm{~mol} \% \mathrm{GeO}_{2}$ co-doped tetragonal $\mathrm{ZrO}_{2}-3$ mol\% $\mathrm{Y}_{2} \mathrm{O}_{3}$ polycrystal (3Y-TZP). 3Y-TZP powder (TZ3Y; Tosoh Co., Ltd.), titanium oxide $\left(\mathrm{TiO}_{2}\right.$, Sumitomo Cement Co., Ltd.) and germanium oxide $\left(\mathrm{GeO}_{2}\right.$, Rare Metallic Co., Ltd.) were used as starting materials. The fabrication procedure of sintered materials is described elsewhere. ${ }^{16,17)}$ The green compacts were sintered at a temperature in the range $1673 \mathrm{~K}$ for $2 \mathrm{~h}$ in air. The average grain size of $0.52 \mu \mathrm{m}$ and the relative density of about $99 \%$ for the theoretical value were obtained in the present materilas. Microstructures were examined with a scanning electron microscope (SEM; JSM-5200, JEOL). The grain size was measured by the linear intercept method using SEM photographs.

High-temperature mechanical experiments were carried out under uniaxial tension in air at a constant cross-head speed using an Instron-type testing machine equipped with a resistance-heated furnace (AG-5000C; Shimazu Co., Ltd.). The initial strain rate and temperature were $1.3 \times 10^{-4} \mathrm{~s}^{-1}$ and $1573-1773 \mathrm{~K}$, respectively. The test temperature was measured by a Pt-PtRh thermocouple attached to each specimen and kept to within $\pm 1 \mathrm{~K}$. The size of the specimens for tensile tests was $2 \times 2 \mathrm{~mm}^{2}$ in cross-section and $13.5 \mathrm{~mm}$ in gauge length.

High-resolution electron microscope (HREM) observations were performed to analyze the grain-boundary structure using a Hitachi H-9000NAR $(300 \mathrm{kV})$ transmission electron microscope. Chemical analysis was carried out by an energy dispersive X-ray spectrometer (EDS; Noran Voyager system) attached to a Topcon EM-002BF $(200 \mathrm{kV})$ field-emission TEM with a probe size of about $1 \mathrm{~nm}$. TEM specimens were prepared using standard techniques involving mechanical grinding to a thickness of $0.1 \mathrm{~mm}$, dimpling to a thickness of $20 \mu \mathrm{m}$ and ion beam milling to electron transparency at about $4 \mathrm{kV}$.
A first-principle molecular orbital calculation was performed by solving the Hartree-Fock-Slater equations selfconsistently using a discrete-variational (DV)-X $\alpha$ method developed by Adachi et al. ${ }^{18)}$ In the DV-X $\alpha$ method, numerical atomic orbitals obtained by solving the Schrödinger equation for atoms were used as the basic function. Model clusters used in the present study were $\left[\mathrm{Y}_{4} \mathrm{Zr}_{18} \mathrm{O}_{86}\right]^{-88}$ for $\mathrm{Y}_{2} \mathrm{O}_{3}$-stabilized TZP, $\left[\mathrm{Ti}_{2} \mathrm{Y}_{4} \mathrm{Zr}_{16} \mathrm{O}_{86}\right]^{-88}$ for $\mathrm{TiO}_{2}$-doped TZP and $\left[\mathrm{TiGeY}_{4} \mathrm{Zr}_{16} \mathrm{O}_{86}\right]^{-88}$ for $\mathrm{TiO}_{2}$ and $\mathrm{GeO}_{2}$-doped TZP, which will be demonstrated in the next section. The model clusters were embedded into a field of Madelung potential composed of 6000 point charges. From the Mulliken population analysis, we can obtain the information of chemical bonding state such as bond overlap population between atoms (BOP) and net charge for each atom (NC). ${ }^{18)}$ $\mathrm{BOP}$ and $\mathrm{NC}$ correspond to covalency between atoms and effective ionic charge for each atom, respectively.

\section{Results and Discussion}

Figure 2 shows stress-strain curves in $2 \mathrm{~mol}^{\%} \mathrm{TiO}_{2}$ and $2 \mathrm{~mol} \% \mathrm{GeO}_{2}$ co-doped $3 \mathrm{Y}-\mathrm{TZP}$ at temperatures between 1573 and $1773 \mathrm{~K}$ under an initial strain rate of $1.3 \times 10^{-4} \mathrm{~s}^{-1}$. For comparison, the stress-strain curve in $\mathrm{Y}-\mathrm{TZP}$ at $1673 \mathrm{~K}$ is also plotted for comparison. ${ }^{13)} \mathrm{TiO}_{2}$ and $\mathrm{GeO}_{2}$ co-doped TZP exhibits huge tensile elongation to failure at high temperatures in comparison with TZP, but the elongation to failure takes a maximum value at the intermediate temperature. On the other hand, the flow stress at early stage of deformation with the strain of less than $10 \%$, in which the grain growth effect can be neglected, is reduced with the increase in the temperature. Moreover, the flow stress at the failure at $1673 \mathrm{~K}$ with the largest tensile ductility takes the highest value in comparison with those at other temperatures. The strain hardening is probably caused by grain growth during deformation. This result demonstrates that the elongation to failure is not simply described in terms of their flow stress.

Figure 3 shows a plot of the grain size at the time of failure $d_{\mathrm{f}}$ against temperature under the initial strain rate of

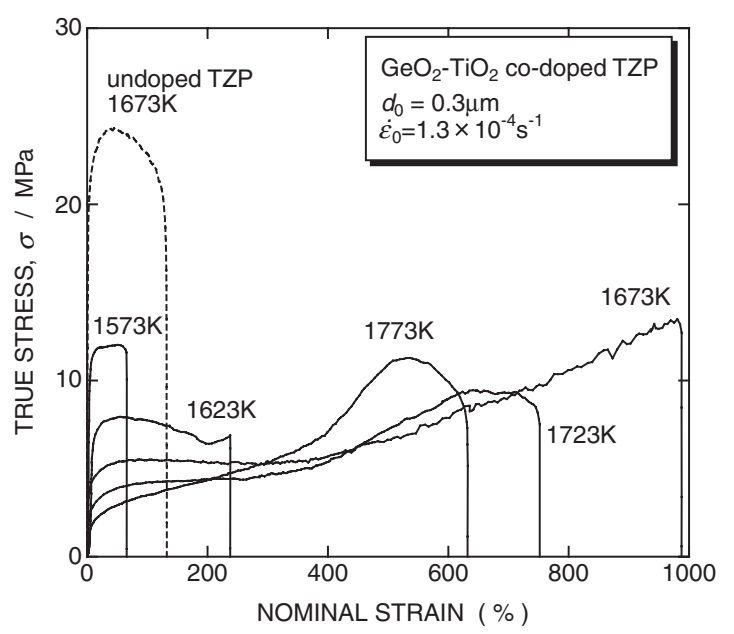

Fig. 2 Stress-strain curves in $2 \mathrm{~mol} \% \mathrm{TiO}_{2}$ and $2 \mathrm{~mol} \% \mathrm{GeO}_{2}$ co-doped TZP at an initial strain rate of $1.3 \times 10^{-4} \mathrm{~s}^{-1}$ at temperatures between 1573 and $1773 \mathrm{~K}$. Stress-strain curve in TZP at $1673 \mathrm{~K}$ is also plotted for comparison. 


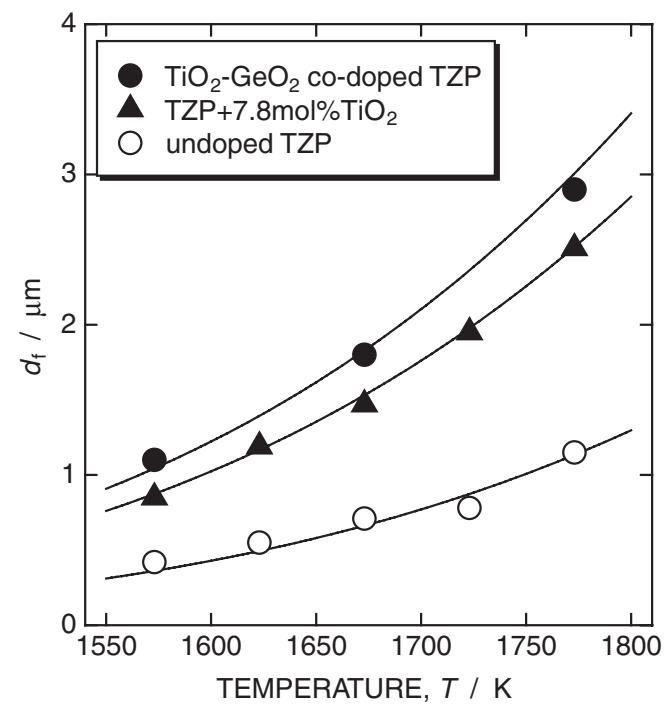

Fig. 3 Temperature dependence of $d_{\mathrm{f}}$ in TZP, TZP-7.8 $\mathrm{mol}_{\%} \mathrm{TiO}_{2}{ }^{13)}$ and $2 \mathrm{~mol} \% \quad \mathrm{TiO}_{2}$ and $2 \mathrm{~mol} \% \quad \mathrm{GeO}_{2}$ co-doped TZP at strain rate of $1.3 \times 10^{-4} \mathrm{~s}^{-1}$. The solid lines are the $d_{\mathrm{f}}$ change with temperature calculated from eq. (1).

$1.3 \times 10^{-4} \mathrm{~s}^{-1}$ in $2 \mathrm{~mol} \% \mathrm{TiO}_{2}$ and $2 \mathrm{~mol} \% \mathrm{GeO}_{2}$ co-doped TZP. The previous data obtained for TZP and TZP5 mass $\%(7.8 \mathrm{~mol} \%) \mathrm{TiO}_{2}$ are also plotted for comparison. ${ }^{13)}$ The value of $d_{\mathrm{f}}$ is increased with increasing temperature in the three materials. The value of $d_{\mathrm{f}}$ is larger in $\mathrm{TZP}-\mathrm{TiO}_{2}$ and is much larger in $\mathrm{TiO}_{2}$ and $\mathrm{GeO}_{2}$ co-doped TZP than in TZP at temperatures examined. The high grain growth rate in $\mathrm{TiO}_{2}$ or $\mathrm{TiO}_{2}$ and $\mathrm{GeO}_{2}$ co-doped TZP is probably caused by the enhanced diffusivity in TZP due to the addition of $\mathrm{TiO}_{2}$ or $\mathrm{GeO}_{2}$. The enhanced static grain growth in $\mathrm{TiO}_{2}$ or $\mathrm{GeO}_{2}$ doped TZP has also been observed in the previous paper. ${ }^{16)}$ The present result is consistent with the previous one.

Figure 4 shows a high-resolution transmission electron microscope image for a grain boundary in $2 \mathrm{~mol} \%$ of $\mathrm{TiO}_{2}$ and $\mathrm{GeO}_{2}$ co-doped TZP. The high-resolution image is in an edge on view condition for the grain boundary. There is no second phase such as grain boundary amorphous layer or second phase particles at the grain boundaries in $\mathrm{TiO}_{2}$ and $\mathrm{GeO}_{2}$ co-doped TZP. Figure 5 shows EDS spectra taken from (a) the grain boundary and (b) grain interior $5 \mathrm{~nm}$ off the grain boundary for $\mathrm{TiO}_{2}$ and $\mathrm{GeO}_{2}$ co-doped TZP. The analyzed points are indicated by circles in Fig. 4. The spectra were obtained by nano-probe EDS using the incident electron beam size of about $1 \mathrm{~nm}$. As shown in the spectra, yttrium, titanium and germanium can be detected not only at the grain boundary but also the grain interior, and the intensity for each cation from the grain boundary is higher than that from the grain interior. This result indicates that the dopant cations tend to segregate at the grain boundaries in $\mathrm{TiO}_{2}$ and $\mathrm{GeO}_{2}$ co-doped TZP. Since the superplastic flow in TZP usually takes place by the matter transport through the grain boundary, ${ }^{19)}$ and since the high temperature failure in finegrained ceramics occurs at the grain boundaries, ${ }^{12)}$ the dopant effect on the superplastic behavior is mainly caused by the segregation of the dopant cations.

The grain boundary diffusion is supposed to be an

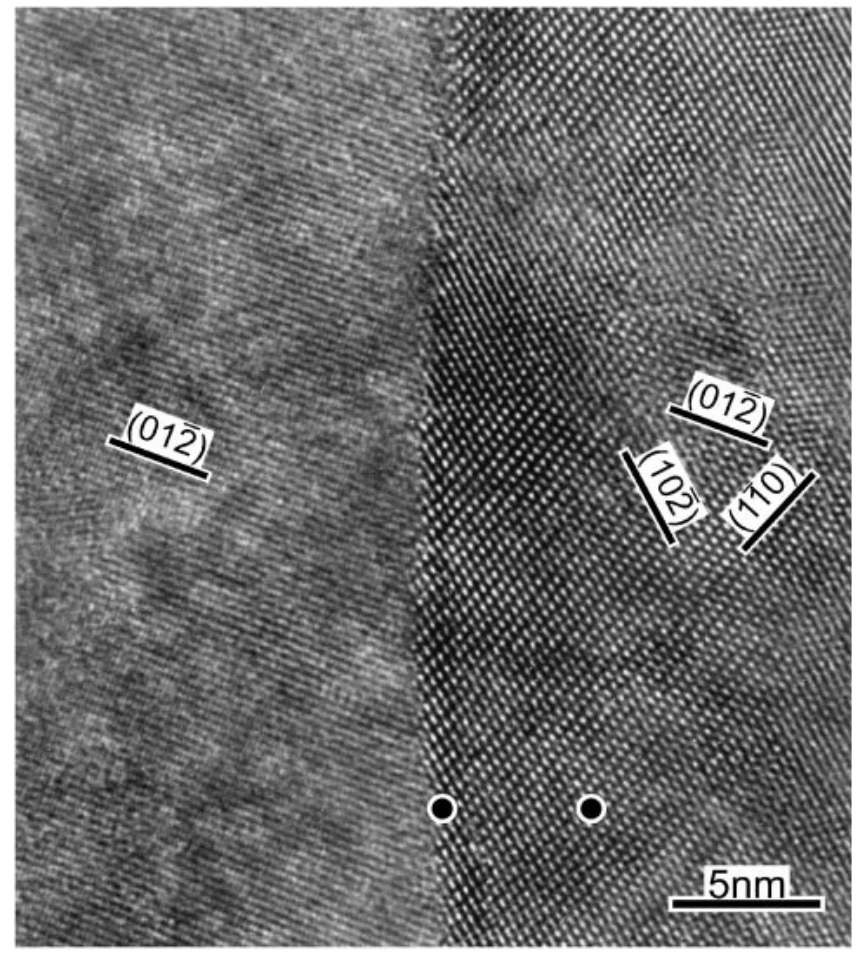

Fig. 4 A high-resolution electron microscopy image of a grain boundary in $2 \mathrm{~mol} \% \mathrm{TiO}_{2}$ and $2 \mathrm{~mol} \% \mathrm{GeO}_{2}$ co-doped TZP.

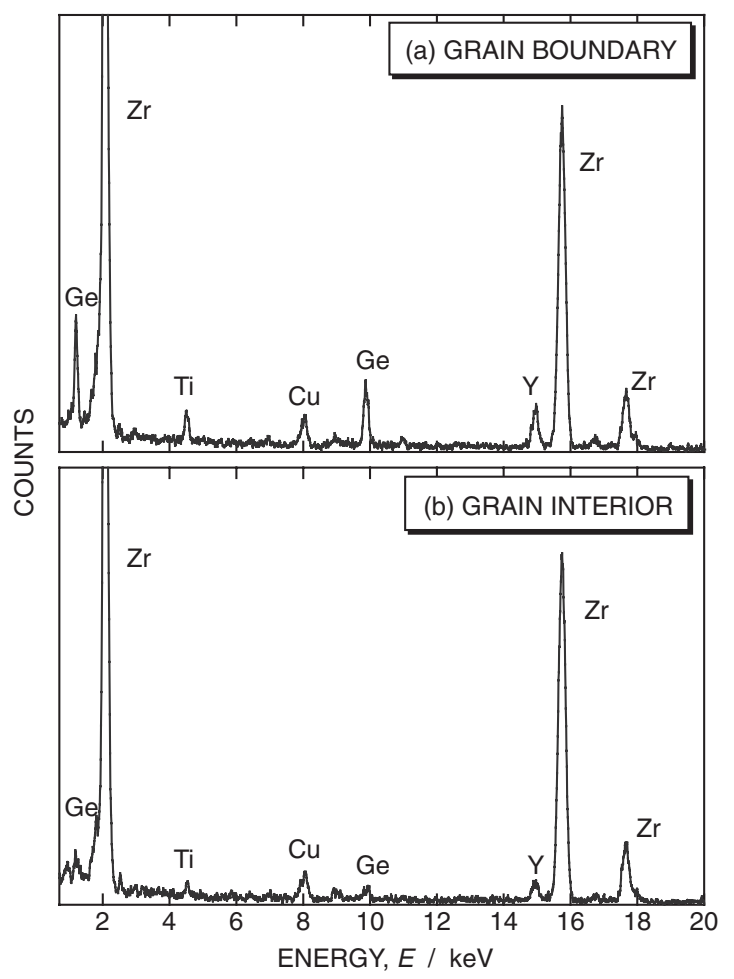

Fig. 5 EDS spectra taken from (a) grain boundary and (b) grain interior $5 \mathrm{~nm}$ off the grain boundary using an incident electron beam size of about $1 \mathrm{~nm}$.

accommodation process for the superplastic flow in TZP. ${ }^{19)}$ However, an enhancement in the diffusivity probably accelerates dynamic grain growth which inhibits the superplastic flow. Therefore, it is possible that temperature dependence of 
the elongation to failure takes a peak value at a certain temperature caused by a difference in temperature dependence of between the superplastic flow and the grain growth rate. In our previous work, the high temperature tensile ductility in superplastic TZP was phenomenologically investigated as a function of strain rate and temperature. ${ }^{13)}$ Assuming the grain size at the time of failure $d_{\mathrm{f}}$ as a parameter to describe a limit of an accommodation process for superplastic flow, the elongation to failure can be estimated from the grain growth behavior during deformation. As indicated in the previous work, ${ }^{13)} d_{\mathrm{f}}$ can be written as a function of temperature by the following equation,

$$
d_{\mathrm{f}}=\frac{C}{\dot{\varepsilon}^{1 / 4}} \exp \left(-\frac{Q_{\text {sup }}}{n R T}\right)
$$

where $C$ is the material constant, $\dot{\varepsilon}$ is the strain rate, $Q_{\text {sup }}$ is the activation energy for superplastic flow, $R T$ is the gas constant times absolute temperature and $n$ is a constant which was estimated to be about $4 .^{20)}$ The value of $d_{\mathrm{f}}$ decreases with increasing the strain rate, ${ }^{13}$ probably because diffusional accommodation process is enhanced at low strain rates. It has been demonstrated that the relationship between $d_{\mathrm{f}}$ and the temperature in TZP and TZP-5 mass $\% \mathrm{TiO}_{2}$ can be well described by eq. (1). ${ }^{13)}$ In Fig. 3, the calculated relationship between $d_{\mathrm{f}}$ and $T$ are plotted by solid lines for TZP, TZP$7.8 \mathrm{~mol}_{\%} \mathrm{TiO}_{2}$ and $2 \mathrm{~mol} \% \mathrm{TiO}_{2}$ and $\mathrm{GeO}_{2}$ co-doped TZP. The substituted values of the activation energy obtained from the superplastic flow ${ }^{13)}$ and $C$ are listed in Table 1 . The calculated curves are in good agreement with the experimental data in the present materials.

Based on a parabolic law of the static grain growth ${ }^{16)}$ and the grain switching model of the high temperature deformation-enhanced grain growth, ${ }^{21)}$ the grain growth during deformation can be described as a function of the temperature and the strain rate $\dot{\varepsilon}{ }^{13)}$ In other words, the relationship between strain and the grain size during deformation can be given for superplastic deformation. At the time of failure, true strain $\varepsilon_{\mathrm{f}}$ can be written as a function of strain rate and temperature,

$$
\begin{aligned}
\frac{C}{\dot{\varepsilon}^{1 / 4}} \exp \left(-\frac{Q_{\text {sup }}}{n R T}\right)= & \left\{d_{0}^{2}+K_{0}\right. \\
& \left.\times \exp \left(-\frac{Q_{\mathrm{gg}}}{R T}\right) \frac{\varepsilon_{\mathrm{f}}}{\dot{\varepsilon}}\right\}^{1 / 2} \exp \left(\alpha \varepsilon_{\mathrm{f}}\right)
\end{aligned}
$$

where $d_{0}$ is the initial grain size, $K_{0}$ is static grain growth constant, $Q_{\mathrm{gg}}$ is the activation energy for the grain growth and $\alpha$ is a proportional constant. $K_{0}$ is taken to be about $1 \times$ $10^{8} \mu \mathrm{m}^{2}$ and $\alpha$ to be about 0.6 in the present materials. ${ }^{13)}$ Figure 6 shows the temperature dependence of experimental

Table 1 The substituted values of activation energy for superplastic flow, activation energy for grain growth and $C$ in the present materials.

\begin{tabular}{lccc}
\hline \multicolumn{1}{c}{ Sample } & $\begin{array}{c}Q_{\text {sup }} \\
\left(\mathrm{kJ} \mathrm{mol}^{-1}\right)\end{array}$ & $\begin{array}{c}Q_{\mathrm{gg}} \\
\left(\mathrm{kJ} \mathrm{mol}^{-1}\right)\end{array}$ & $\begin{array}{c}C \\
\left(\mu \mathrm{m} \mathrm{s}^{1 / 4}\right)\end{array}$ \\
\hline $\mathrm{TiO}_{2}-\mathrm{GeO}_{2}$ co-doped TZP & 460 & 400 & 1320 \\
$\mathrm{TZP}^{-\mathrm{TiO}_{2}}$ & 472 & 405 & 1100 \\
$\mathrm{TZP}$ & 530 & 455 & 970 \\
\hline
\end{tabular}

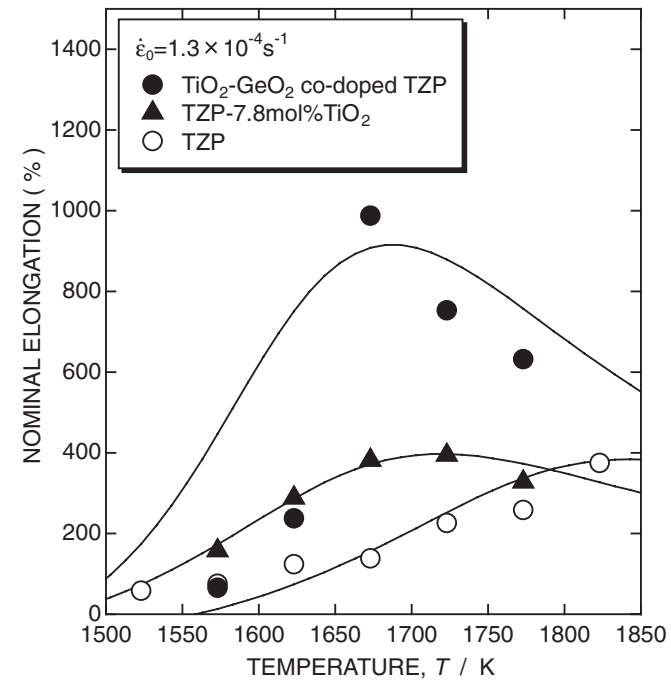

Fig. 6 Temperature dependence of experimental and calculated elongation to failure in TZP, TZP-7.8 $\mathrm{mol}_{\%} \mathrm{TiO}_{2}{ }^{13)}$ and $2 \mathrm{~mol} \% \mathrm{TiO}_{2}$ and $2 \mathrm{~mol} \%$ $\mathrm{GeO}_{2}$ co-doped TZP at strain rate of $1.3 \times 10^{-4} \mathrm{~s}^{-1}$.

and calculated elongation to failure in $2 \mathrm{~mol} \% \mathrm{TiO}_{2}$ and $2 \mathrm{~mol} \% \mathrm{GeO}_{2}$ co-doped TZP. The data for TZP and TZP$7.8 \mathrm{~mol}_{\%} \mathrm{TiO}_{2}{ }^{13)}$ are also plotted for comparison. A fairly good agreement between observed and calculated results is obtained for each material. As seen in this figure, temperature dependence of the elongation to failure takes a peak value at a certain temperature. Therefore, the tensile ductility in $\mathrm{TiO}_{2}$ $\mathrm{GeO}_{2}$ co-doped TZP is highly improved, at temperatures around $1673 \mathrm{~K}$, but is not always improved by $\mathrm{TiO}_{2}$ or $\mathrm{GeO}_{2}$ doping. It should be noted that the elongation to failure in $\mathrm{TiO}_{2}-\mathrm{GeO}_{2}$ co-doped TZP is significantly lower than the calculated value, rather close to that in $\mathrm{TiO}_{2}$-doped TZP at around $1600 \mathrm{~K}$. The result is probably related to the segregation behavior of $\mathrm{Ti}$ and $\mathrm{Ge}$ cations at the temperature. Further investigation of the segregation behavior in deformed samples will provide more quantitative agreement between the experimental and theoretical data.

As discussed in our previous paper, ${ }^{20)} Q_{\text {sup }}$ and $Q_{\text {gg }}$ are the main parameters to determine the elongation to failure in superplastic ceramics. The peak value of elongation to failure decreases, and the temperature region for superplastic flow lowers with a reduction of the activation energies. ${ }^{20)}$ This must be the situation of $\mathrm{TiO}_{2}$ doping into TZP. Another factor influencing the tensile ductility is $C$. It has experimentally been verified that the flow stress increases with an increase of grain size in fine-grained TZP. ${ }^{7)}$ When the stress concentration at multiple junctions reaches a level to give a critical grain size during deformation, cavities are introduced at the multiple junctions and specimens finally fail. ${ }^{7)}$ In other words, cavities begin to interconnect and intergranular failure takes place over the critical stress given by $d_{\mathrm{f}}$. Therefore, the value of $C$ is supposed to be a critical parameter, which correlates with the fracture resistance of the grain boundaries in superplastic ceramics. Figure 7 demonstrates the effect of the value of $C$ on the temperature dependence of elongation to failure in $2 \mathrm{~mol} \% \mathrm{TiO}_{2}$ and $\mathrm{GeO}_{2}$ co-doped TZP. The reduction of $C$ from $1320 \mu \mathrm{m} \cdot \mathrm{s}^{1 / 4}$ to $970 \mu \mathrm{m} \cdot \mathrm{s}^{1 / 4}$ for $\mathrm{TiO}_{2}$ and $\mathrm{GeO}_{2}$ co-doped TZP causes a reduction in the value of 


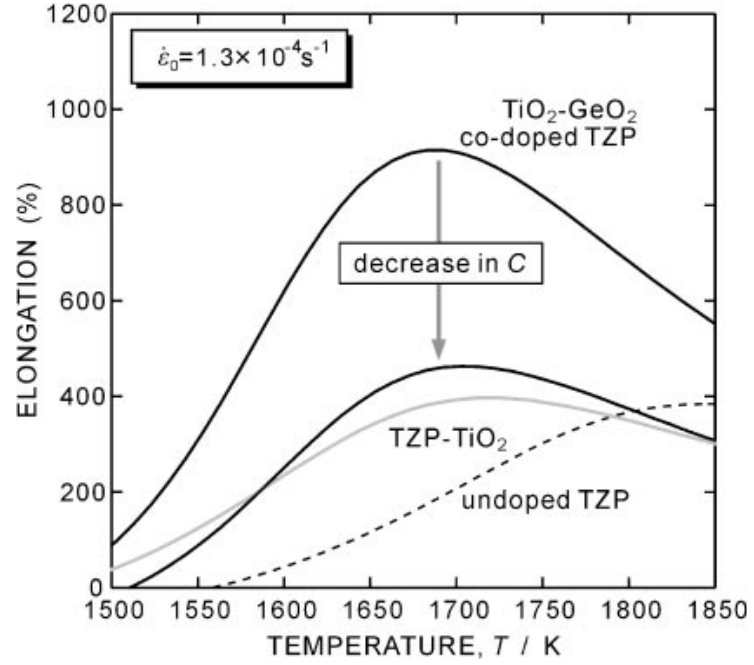

Fig. 7 Individual effect of $C$ on the temperature dependence of the elongation to failure. A reduction of $C$ is considered for $2 \mathrm{~mol}^{2} \mathrm{TiO}_{2}$ and $2 \mathrm{~mol} \% \mathrm{GeO}_{2}$ co-doped TZP.

elongation. This fact demonstrates that an increase of $C$ has an effect of increasing the tensile elongation. The present result seems to be consistent with the speculation described above that the value of $C$ can be regarded as a parameter which gives a critical stress for high temperature failure in TZP.

A first-principle molecular orbital calculation was made by $\mathrm{DV}-\mathrm{X} \alpha$ method to estimate the change in the chemical bonding state due to the presence of titanium and germanium cations. Figure 8(a) shows the model cluster $\left[\mathrm{Y}_{4} \mathrm{Zr}_{18} \mathrm{O}_{86}\right]^{-88}$ used for the calculation. In this cluster, two yttrium ions are substituted at the third nearest neighbor from a zirconium site $\mathrm{Zr}_{1}$ indicated in this figure. An oxygen vacancy for maintaining electronic neutrality is introduced at the mutual second nearest neighbor sites from the two yttrium cations. ${ }^{22)}$ Other two yttrium cations are also located at the third nearest neighbor sites from $\mathrm{Zr}_{2}$ site and an oxygen vacancy is introduced at the second nearest neighbor from the two yttrium cations. $\left[\mathrm{Ti}_{2} \mathrm{Y}_{4} \mathrm{Zr}_{16} \mathrm{O}_{86}\right]^{-88}$ and $\left[\mathrm{TiGeY}_{4} \mathrm{Zr}_{16} \mathrm{O}_{86}\right]^{-88}$ clusters, in which $\mathrm{Ti}$ and $\mathrm{Ge}$ cations are substituted at $\mathrm{Zr}_{1}$ and $\mathrm{Zr}_{2}$, were made for the model clusters of $\mathrm{TiO}_{2}$-doped $\mathrm{TZP}$ and $\mathrm{GeO}_{2}$ and $\mathrm{TiO}_{2}$ co-doped TZP, respectively. A good correlation can be found between the value of $C$ and overlap population between atoms in the model clusters. Figure $8(\mathrm{~b})$ shows a plot of $C$ against total value of bond overlap population in the model clusters. The total value corresponds to a summation of all BOP between cations and anions in each model cluster. As seen in this figure, the value of $C$ increases with increase of overlap population, which indicates improvement of the covalency between atoms. Since the value of $C$ can be regarded as a critical parameter for high temperature failure, and since the intergranular failure takes place in superplastic TZP, ${ }^{12)}$ the present result indicates that resistance to intergranular failure increases with the increase of covalent bond strength, and the tensile elongation to failure in TZP is increased by $\mathrm{TiO}_{2}$ and $\mathrm{GeO}_{2}$ co-doping. The covalent bonding is thus a critical factor in the tensile ductility of superplastic TZP. (a)
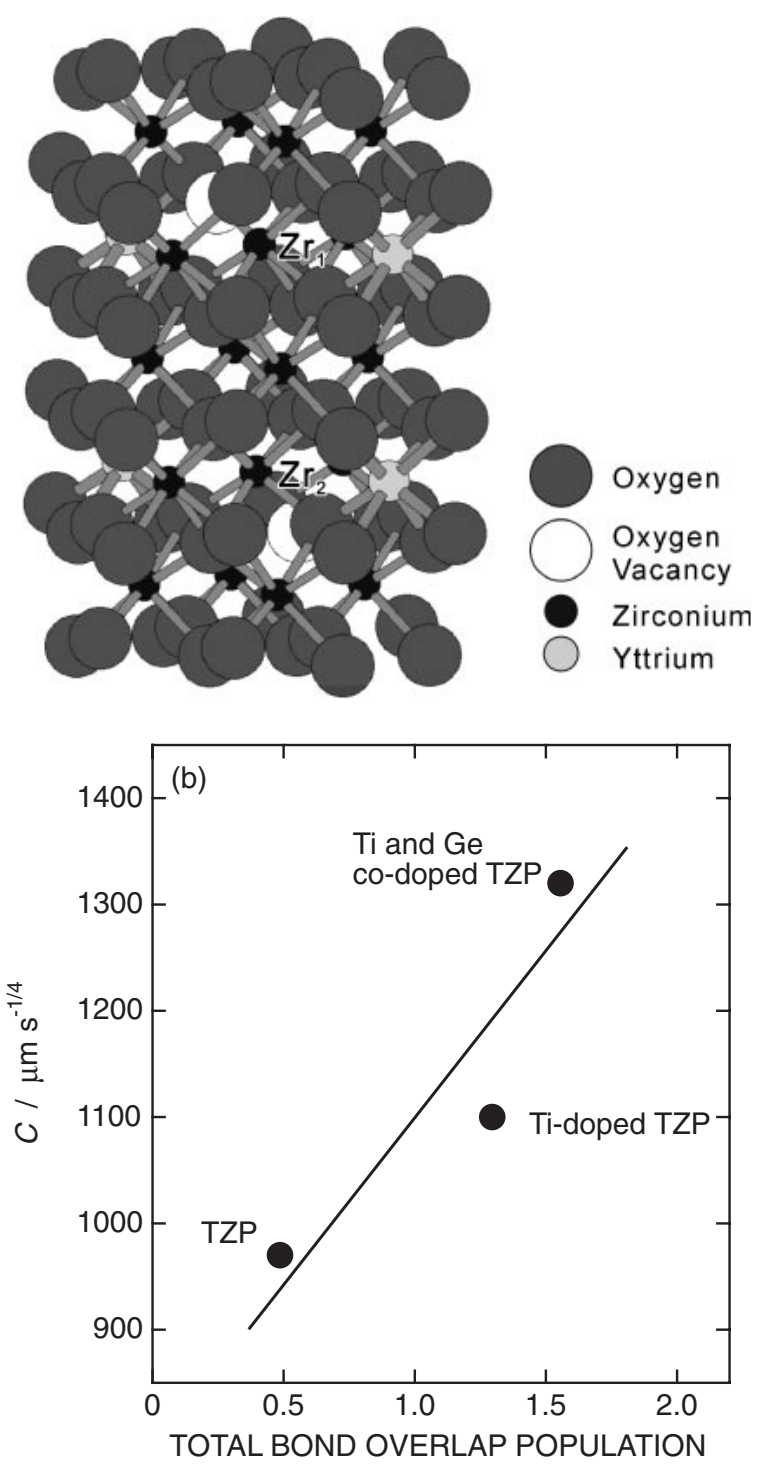

Fig. 8 Model cluster of TZP used for a first-principle molecular orbital calculation (a) and the relationship between the value of $C$ and the total BOP in TZP, Ti-doped TZP and Ti and Ge co-doped TZP (b).

\section{Conclusion}

Temperature dependence of high temperature elongation to failure in $2 \mathrm{~mol}^{\circ} \mathrm{TiO}_{2}$ and $2 \mathrm{~mol}_{\%} \mathrm{GeO}_{2}$ co-doped TZP was examined at temperatures between 1573 and $1773 \mathrm{~K}$. The improvement in the high temperature ductility in TZP due to $\mathrm{TiO}_{2}$ and $\mathrm{GeO}_{2}$ co-doping is attributed to segregation of the dopant cations in the vicinity of the grain boundaries. The co-doping of Ti and Ge cations increases the grain size at the time of failure, which can be regarded as a parameter to give a limit of stress for high temperature failure. The parameter of the critical grain size at the time of failure correlates well with the value of overlap population in cationdoped TZP model cluster obtained from a first-principle molecular orbital calculation. The covalent bond at the grain boundaries plays a critical role in the high temperature tensile ductility of TZP. 


\section{Acknowledgements}

The authors wish to express their gratitude to the Ministry of Education, Culture, Sports, Science and Technology and Japan Society for the Promotion of Science for the financial support by a Grant-in-Aid for Scientific Research on Priority Areas and for Encouragement of Young Scientists. We also wish to express our thanks to Nippon Sheet Glass Foundation for Materials Science and Engineering for their financial aid.

\section{REFERENCES}

1) F. Wakai, S. Sakaguchi and Y. Matsumoto: Adv. Ceram. Mater. 1 (1986) 259-263.

2) T. G. Nieh, C. M. McNelly and J. Wadworth: Scr. Metall. 22 (1988) 1297-1300.

3) T. G. Nieh and J. Wadworth: Acta. Metall. Mater. 38 (1990) 11211133.

4) I.-W. Chen and L. A. Xue: J. Am. Ceram. Soc. 73 (1990) 2585-2609.

5) Y. Ma and T. G. Langdon: Mater. Sci. Eng. A168 (1993) 225-230.

6) A. H. Chokshi, A. K. Mukherjee and T. G. Langdon: Mater. Sci. Eng. R10 (1993) 237-274.

7) K. Kajihara, Y. Yoshizawa and T. Sakuma: Acta Metall. Mater. 43 (1995) 1121-1133.

8) M. Jimenez-Melend, A. Dominguez-Rodoriguez and A. Bravo-Leon: J. Am. Ceram. Soc. 81 (1998) 2761-2776.

9) J. Hines, Y. Ikuhara, A.H. Chokshi and T. Sakuma: Acta Mater. 46
(1998) 5557-5568.

10) M. Oka, N. Tabuchi and T. Takashi: Mater. Sci. Forum 304-306 (1999) 451-458.

11) K. Sasaki, M. Nakano, J. Mimurada, Y. Ikuhara and T. Sakuma: Mater. Sci. Forum 357-359 (2001) 129-134.

12) W.-J. Kim, J. Wolfenstine and O. D. Sherby: Acta Metall. Mater. 39 (1991) 199-208.

13) T. Kondo, Y. Takigawa and T. Sakuma: Mater. Sci. Eng. A231 (1997) 163-169.

14) A. Kuwabara, S. Yokota, Y. Ikuhara and T. Sakuma: Mater. Sci. Forum 357-359 (2001) 399-404.

15) H. Yoshida, Y. Takigawa, Y. Ikuhara and T. Sakuma: Mater. Trans. 43 (2002) 1566-1572.

16) H. Yoshida, H. Nagayama and T. Sakuma: Mater. Trans. 44 (2003) 935-939.

17) Y. Yoshizawa and T. Sakuma: Acta Metall. Mater. 40 (1992) 29432950.

18) H. Adachi, H. Adachi, M. Tsukada and C. Satoko: J. Phys. Soc. Jpn. 45 (1978) 875-883.

19) S. Primdahl, A. Thölen and T. G. Langdon: Acta Metall. Mater. 43 (1995) 1211-1218.

20) T. Kondo, Y. Takigawa, Y. Ikuhara and T. Sakuma: Mater. Trans. 39 (1998) 1108-1114.

21) E. Sato, K. Kribayashi and R. Horiuchi: Superplasticity and Superplastic Forming, Ed. by C. H. Hamilton and N. E. Paton, (TMS, Warendale, PA, 1988) p. 115.

22) P. Li, I.-W. Chen and J. E. P. Hahn: J. Am. Ceram. Soc. 77 (1994) 118 128. 